\title{
Tooling Materials and Solutions for Thixoforming of Steel RASSILI Ahmed ${ }^{1, a}$, FALZONE Salvatore, a and LECOMTE-BECKERS Jacqueline ${ }^{1, b}$
}

${ }^{1}$ ThixoUnit ULg, Aerospace and Mechanical Engineering, University of Liège, 4000 Liège, Belgium

aa.rassili@ulg.ac.be, bJacqueline.Lecomte@ulg.ac.be

Keywords: Thixoforging, steel, high melting point, tool material.

Abstract. The aim of this work is to evaluate the thermal and mechanical loadings applied to the tools during steel thixoforming process in order to determine appropriate tool materials and solutions. This evaluation was realized thanks to experimental trials and to the finite elements simulations. The effect of these loadings on the tool's failure modes are highlighted and compared to the ones observed in classical forming processes. Beyond this, the failure modes of different tool materials and solutions are presented. The tested materials are hot-working tool steels. Other possibilities and tool coating or surface treatments are discussed as well.

\section{Introduction}

Due to high slug temperature (usually higher than $1350^{\circ} \mathrm{C}$ ), tools surfaces reach very high temperature. In hot forging, this temperature could already reach $500^{\circ} \mathrm{C}$ [1-3]; in thixoforging, tool temperature increase could reach $700^{\circ} \mathrm{C}$ and even higher. Such a temperature is higher than classical tool steels annealing temperature and could lead to a fall of the mechanical properties. In order to minimize the thermal shocks, dies are usually pre-heated from 40 to $350^{\circ} \mathrm{C}$ in hot forging, but this does not prevent the temperature from increasing.

Thixoforging process, as hot forging is composed of three sequential steps:

- Brutal contact of high temperature slug on the tool. If needed, tool closing could be done before or after this step.

- Forming step during which mechanical constraints are applied to the tool.

- Part ejection and tool cooling.

In production, these steps are repeated in a cycle. Tool damaging could be due to different mechanisms: fatigue cracking following thermomechanical loading cycle, microstructure evolution or scaling due to hot working, geometrical modification generated by wearing or plastic deformation. These machanisms are commonly known as: (1) abrasive wearing, (2) thermal fatigue, (3) mechanical fatigue, (4) plastic deformation [4]

In thixoforging, thermomechanical loadings are quite different as forming loads are lower but thermal loads are higher. The failure modes could be different too or simply accentuated. Their determination is the first aim of this paper as well as a set of solutions either in terms of materials or coatings.

\section{Experimental Investigations}

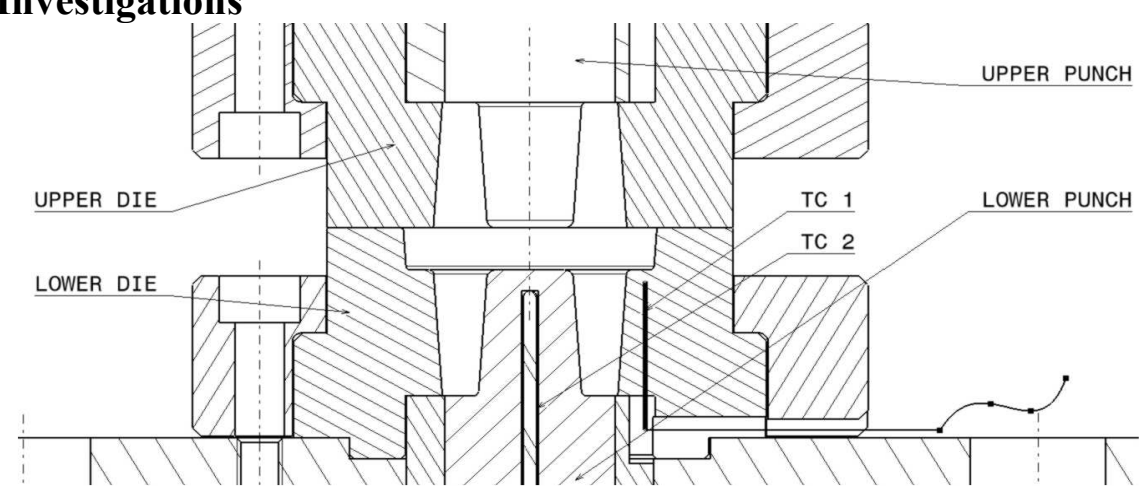

Fig.1 Axisymmetric H shape tool. TC1 and TC2 stand for thermocouples measurment. 
Tool design. The tool used during this work (Fig. 1) forms an axisymmetric $H$ shape part. The deformation is a compression followed by an important reverse than a direct extrusion. Due to small thickness of the walls, this geometry highlights the thermal and stress effects occurring during forming. The dies and the punches are instrumented by thermocouples in order to measure their inner thermal fields. At the beginning of cycle, the tool is open and the punches are out of the dies. When heating is done, robot puts the slug in the lower die and moves back. Then, the upper part of the tool moves down to close it and the two punches form the part. It is also possible to form it with the upper punch alone if the lower one is already inside the die at the beginning of cycle or consolidated to this one. This tool is also used to determine friction parameters [5].

Tool Material. Tool has been made of two different tool materials and compared to classical Z38 hot working tool steel. The latter has a good thermal shocks resistance thanks to the presence of chrome, molybdenum and vanadium. It is commonly used as die material in hot forging [6]. The $\mathrm{X} 38 \mathrm{CrMoV} 5$ composition is given on Table 1.

Chrome, molybdenum and vanadium precipitate carbides which increase wearing resistance. Chrome and molybdenum delay the softening due to annealing. Chrome and vanadium inhibit the grains coarsening during austenitizing and chrome and silicon increase scaling resistance.

Table 1 Mass composition of X38CrMoV5 hot working tool steel [6]

\begin{tabular}{cccccccc}
\hline & $\mathrm{C}$ & $\mathrm{Cr}$ & $\mathrm{Mn}$ & $\mathrm{V}$ & $\mathrm{Ni}$ & $\mathrm{Mo}$ & $\mathrm{Si}$ \\
\hline$[\%]$ & 0.40 & 5.05 & 0.49 & 0.47 & 0.20 & 1.25 & 0.92 \\
\hline
\end{tabular}

Nevertheless, this steel grade looses a part of its mechanical properties at high temperature. Table 2 gives the mechanical properties of X38CrMoV5 for four working temperatures for a material previously oil-quenched from $1040^{\circ} \mathrm{C}$ after two tempering at $640^{\circ} \mathrm{C}$. At $600^{\circ} \mathrm{C}$, yield strength is nearly divided by two. Extrapolated until $800^{\circ} \mathrm{C}$, Rp0.2 falls to $400 \mathrm{MPa}$, so lower than the locking force applied on the dies. Moreover, the austenitizing beginning temperature $\left(830^{\circ} \mathrm{C}\right)$ is close to the working one [7].

Table 2 Mechanical properties of X38CrMoV5 at different working temperatures [7]

\begin{tabular}{cccc}
\hline $\begin{array}{c}\text { Temperature } \\
{\left[{ }^{\circ} \mathrm{C}\right]}\end{array}$ & $\mathrm{Rm}[\mathrm{MPa}]$ & $\mathrm{Rp} 0.2[\mathrm{MPa}]$ & $\mathrm{A}[\%]$ \\
\hline 20 & 1400 & 1170 & 12 \\
400 & 1170 & 1020 & 13 \\
500 & 1050 & 900 & 18 \\
600 & 810 & 700 & 25 \\
\hline
\end{tabular}

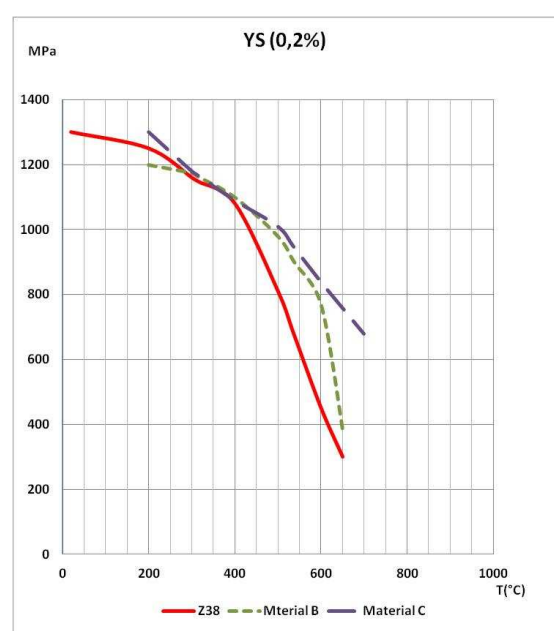

Fig.2 Yield strength of the investigated tool materials compared to Z38 
Fig. 2 shows the yield strength of the two investigated tool materials compared to Z38. At this stage of analysis, we could notice that these two materials will exhibit a more interesting behaviour at high temperature as their yield strength doesn't drop drastically at $600{ }^{\circ} \mathrm{C}$ especially for material $\mathrm{C}$.

Modeling. The Finite Elements code Forge2011 C was used for the simulations. The constitutive law used in this work is quite simple and mainly driven by the liquid fraction, and so the temperature. Thus, the structure of the raw material and its evolution are not explicitly represented. Even if this is a limitation of the calculation results, the error on the flow behavior is small for high solid fraction. Thermal exchanges are already taken into account by the FE code.

The constitutive law is a classical Spittel one (which is the default law used by the solver) when material temperature is lower than solidus and a modification of this Spittel equation when the material temperature is higher than solidus. The modification induces a linear decrease of the consistency by multiplying it by a factor going from one to zero between the solidus and the liquidus. There is then a smooth transition between semi-solid and solid behavior during cooling.

The constitutive law is

$$
\begin{gathered}
\sigma=A e^{m 1 T} \varepsilon^{m 2} e^{\frac{m 4}{\varepsilon}} \dot{\mathcal{E}}^{m 3} \cdot \\
\sigma=A\left(\frac{T_{l i q}-T}{T_{l i q}-T_{s o l}}\right) e^{m 1 T} \varepsilon^{m 2} e^{\frac{m 4}{6}} \dot{\mathcal{E}}^{m 3}
\end{gathered}
$$$$
\text { for } \mathrm{T}<\text { Tsolidus and }
$$

$$
\text { for Tsolidus }<\mathrm{T}<\text { Tliquidus }
$$

Table 3 Values of the constants used in equations (1) and (2)

\begin{tabular}{cc}
\hline Parameter & Value \\
\hline $\mathrm{A}$ & 2707.108 \\
$\mathrm{~m} 1$ & -0.00325 \\
$\mathrm{~m} 2$ & -0.00325 \\
$\mathrm{~m} 3$ & 0.1529 \\
$\mathrm{~m} 4$ & -0.05494 \\
$\mathrm{~T}_{\text {sol }}$ & $1315^{\circ} \mathrm{C}$ \\
$\mathrm{T}_{\text {liq }}$ & $1480^{\circ} \mathrm{C}$ \\
\hline
\end{tabular}

In these equations, $\sigma$ is the stress, $\varepsilon$ is the strain, $\dot{\varepsilon}$ is the strain rate, $\mathrm{T}$ is the temperature, $\mathrm{T}_{\text {liq }}$ is the liquidus temperature, $\mathrm{T}_{\mathrm{sol}}$ is the solidus temperature and $\mathrm{A}, \mathrm{m} 1, \mathrm{~m} 2, \mathrm{~m} 3$ and $\mathrm{m} 4$ are constants depending on the steel grade. For $100 \mathrm{Cr} 6$ steel, the values of the constant parameters are given in Table 3. The values of $\mathrm{A}$ and $\mathrm{m} 1$ to $\mathrm{m} 4$ come from the database of Forge2011(C) and the values of $\mathrm{T}_{\text {liq }}$ and $\mathrm{T}_{\text {sol }}$ have been obtained by Differential Scanning Calorimetry (DSC) [8].

\section{Results and discussion}

Mechanical Loading. In the case of thixoforming, mechanical loadings are about ten to twenty times lower than in hot forging [9, 10]. Fig.3 shows the Von Mises equivalent stresses, calculated by the Forge2011 C software, at the end of forming inside the lower part of the tool. The simulated forming is a $100 \mathrm{Cr} 6$ steel slug symmetrically deformed with a tool speed of $170 \mathrm{~mm} / \mathrm{s}$. It appears that maximum stress, for the areas in contact with the semi-solid material, is around $260 \mathrm{MPa}$. This maximum stress is located in the center of the punch top surface. If the punch temperature reaches a value for which its material yield stress is lower than $260 \mathrm{MPa}$, there would be a deformation of this punch.

The simulation did not take into account the locking force applied to the dies to keep the tool closed. In the present case, this force is $2000 \mathrm{kN}$. Depending on the locked surface, the pressure could be as high as $630 \mathrm{MPa}$. 


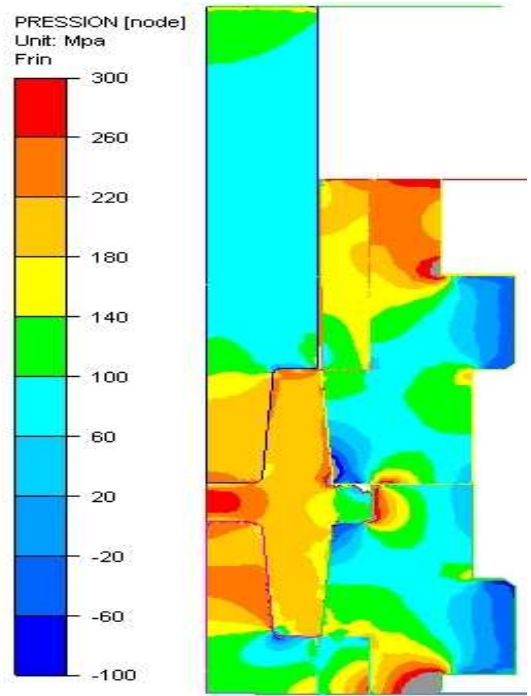

Fig.3 Von Mises equivalent stresses inside the tool at the end of forming

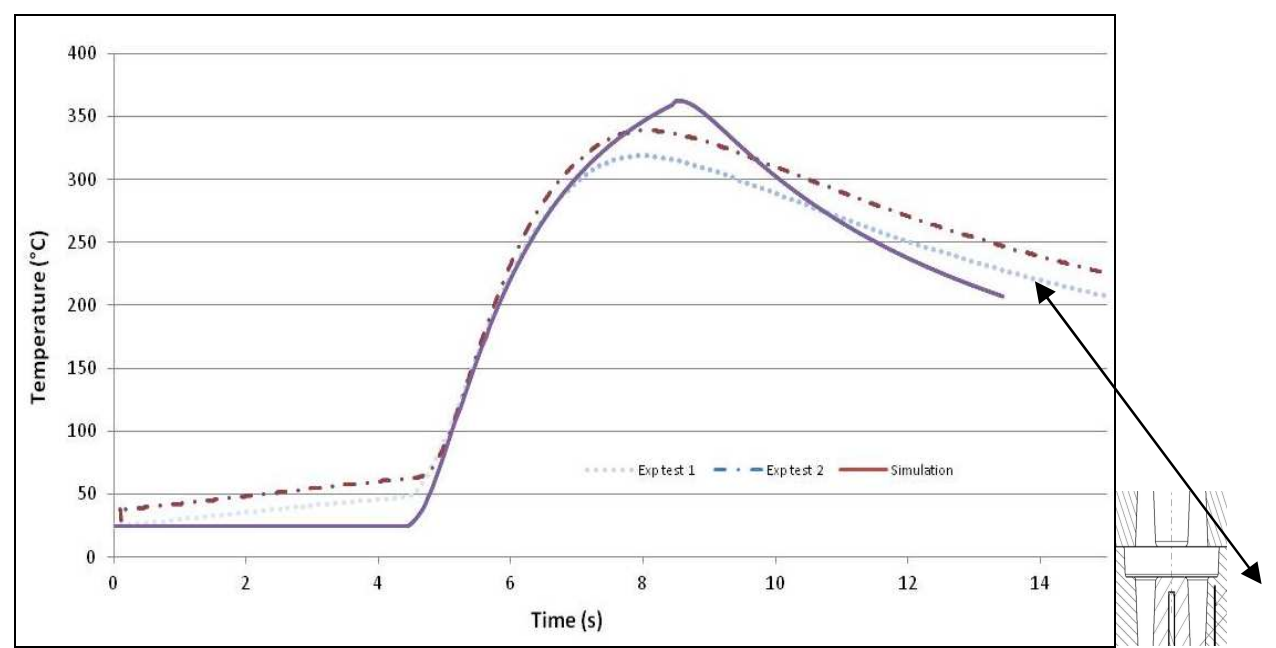

Fig.4 Comparison of the temperatures inside the tool measured by thermocouples (dashed) and calculated by Forge2011 (C) (continue)

Thermal Loading. In hot forging, slugs are usually heated at a temperature higher than $1000^{\circ} \mathrm{C}$. Their contact with the dies could heat these ones up to $500^{\circ} \mathrm{C}$. In thixoforming, the working temperatures are still higher, until more than $1400^{\circ} \mathrm{C}$. Tools surfaces are then subjected to very high temperature. The $\mathrm{H}$ shape tool has been designed in order to be instrumented by thermocouples (TC1 and TC2 in Fig. 2). The measures of these thermocouples allowed validating the temperature fields calculated by simulation, as shown on Fig.4. The aim of the comparison is to show that simulation investigations could be of great help in order to determine better solutions for tool materials prior to any costing experimental investigations.

Fig.5 shows the temperature fields inside the lower part of the tool for the whole forming process. Simulation shows that, at the moment of the ejection, the surface temperature could reach $1100^{\circ} \mathrm{C}$ in the punch and about $580^{\circ} \mathrm{C}$ in the lower die. In this case, if the stresses are important, because of galling during the ejection for example the tool could easily be damaged.

Simulation has been run for tool material C. In the case of another tool material, and thus another thermal conductivity, the surface temperature should be different. In the case of a lower thermal conductivity, the surface temperature would be higher, which will be interesting from the forming point of view as the flowing material temperature would stay higher during a longer time and thus, the forming load would be lower. At the opposite, from the tool point of view, this higher surface temperature would increase the risk to overrun the tool material yield stress and to damage the tool. Thermal stresses, coming from thermal gradients, depend of these gradients value and of the thermal dilatation coefficient. The effects of these thermal stresses are shown in Figs. 6, 7 and 8. 


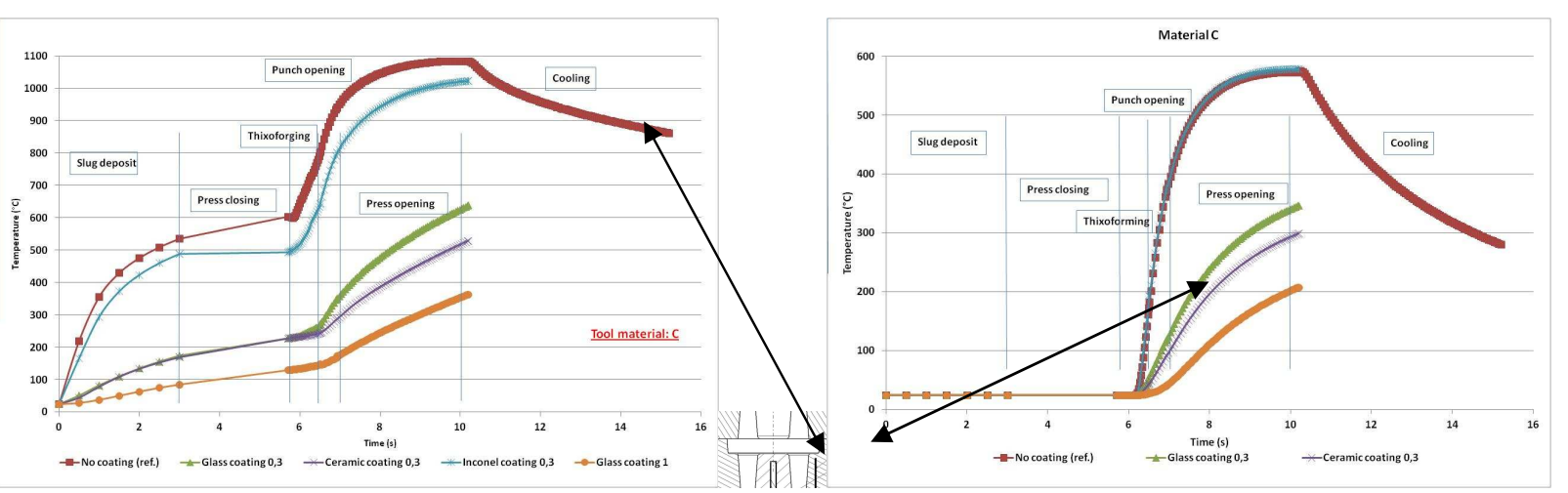

Fig.5 Temperature fields inside the tool surface: lower punch (left) and lower die (right)

Wearing. Fig.6 shows the area of maximum wearing. As in hot forging, they are located where sliding speeds are higher, thus mainly at the punch edge. On the die, there is not any wearing at the joining plane level as the tangential speed is equal to zero on this area in the case of a symmetric deformation. As the working temperature is higher in thixoforming, the tool wearing resistance is lower than in hot forging.

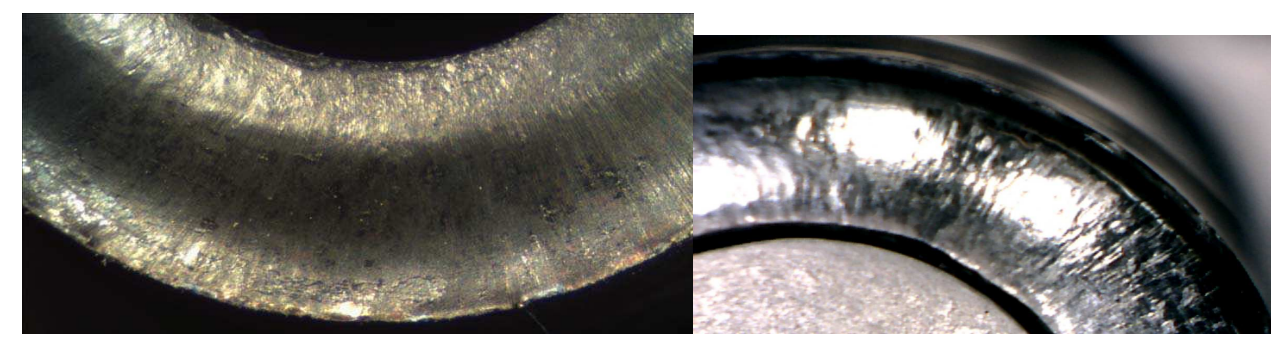

Fig.6 Wearing areas inside the tool

Hardness. Hardness of the tooling's lower punch has been measured after 50 cycles of forming. Fig.7 shows the hardness values measured on the punch and the line along which the measured have been made.

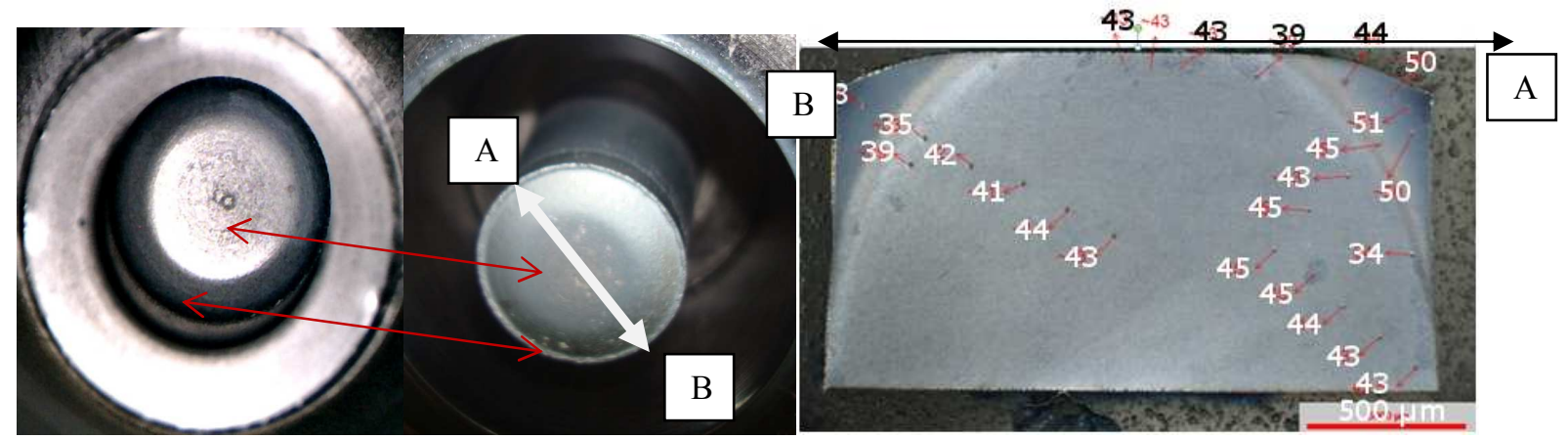

(a)

(b)

(c)

Fig.7 Profile comparison on the punch after 26 (a) and 50 forming cycles (b). Hardness measured along the lower punch after 50 parts forming (section cut A - B of Fig. 8) (c)

The graph shows that the lower and middle parts of the punch have kept their original hardness, around 43-45 HRC. But the hardness of the corners has noticeably increased to 51 HRC due to tempering after annealing. The area between has a hardness between 32 to $39 \mathrm{HRC}$. This softening is due to annealing occurring at high temperature. This means that the punch is more easily deformable. Moreover, some marks are visible on the punch surface, due to galling and abrasive wearing.

Mechanical Resistance. Figs. 7(a-b) and Fig. 8 give profile measures of the upper punch (Fig.7) and die (Fig.8). These profiles have been measured on different points in order to limit the impact of local damages. The profile of the punch lateral surface (Fig.7) shows significant modification of the shape. It seems that mechanical resistance of the punch is not high enough to avoid plastic deformation. 

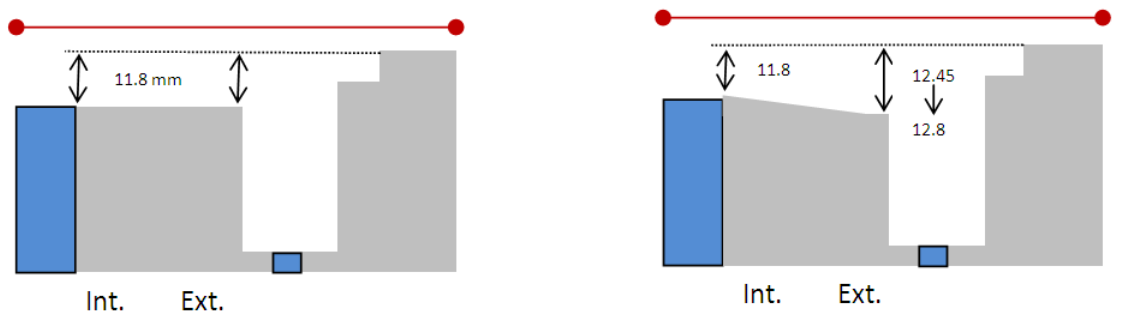

Fig. 8 Profile measures on the die before (left) and after 50 parts forming (right)

The top surface of the die shows important modifications (6 to 10 tenth of millimeter) at the joining plane level. This is due to the friction of the hottest contact zone which induces important stresses (about 300MPa). Around this joining plane, the temperature could reach $570^{\circ} \mathrm{C}$ (Fig. 5).

\section{Conclusions and remarks}

Up to now, thixoforming tool lifetime is still the main lock to the technology industrialization. Due to high working temperature, mechanical features of the hot work tool steels classically used in hot forging strongly decrease. In particular, hardness and yield stress are too low to guarantee the tooling integrity.

Plastic deformation is the main issue. It is due to mechanical and thermal stresses. Compared to hot forging, mechanical stresses are clearly lower but thermal stresses are higher. However, at industrial production rate (6-12 parts per minute), the working temperature should be higher but temperature variation would be lower, so the thermal fatigue should be lower than in the case of laboratory study. To minimize the thermal loadings, tool materials and solutions exit and give good results as shown in Fig. 6. An important point is also to minimise the contact time between tool and semi-solid steel in order to minimize the tool temperature. Parts ejection must then be as fast as possible to decrease thermal loading.

\section{Acknowledgement}

The authors gratefully acknowledge the University of Liège and the Walloon Region for their financial support.

\section{References}

[1] G Andreis, K.D. Fuchs, I. Schruff, The wear behaviour of hot-work tool steels used in forging process, Proceedings of the $5^{\text {th }}$ International Conference on Tooling.(1999) 593-600.

[2] S.Walter, H. Haferkamp, M. Niemeyer, F.W.Bach, A. Henze, Material failure mechanisms of forging dies, Proceedings of the 5the international Conference on Tooling. (1999) 215-224.

[3] D. Kircher, H. Michaud, V. Bogard, Hot forging tools failure analysis by the help of numerical simulation, Mat \& Tech. 1/2 (1999) 31-38

[4] ASM Handbook, Forming and Forging, ASM Publisher, 1998.

[5] J. C. Pierret, A. Rassili, G. Vaneetveld, R. Bigot, J. Lecmote-Beckers, Friction coefficients evaluation for steel thixoforging. Int. Journal of Material Forming, 3(1) (2010) 763 - 766.

[6] O. Barreau, Friction and wearing study for hot-working tool steel, Institut National Polytechnique de Grenoble (2004), PhD Thesis

[7] R. Leveque, Tool steels: Unormalised numerical data, on http://www.techniques-ingenieur.fr

[8] J. Lecmote-Beckers, A. Rassili, M. Robelet, C. Poncin, R. Koeune, Study of the liquid fraction and thermophysical properties of semi-solid steels and application to the simulation of inductive heating for thixoforming, Advanced Methods in Material Forming, (2005) 321-347

[9] R. Bigot, V. Favier, C. Rouff, Characterisation of semi-solid material mechanical behavior by indentation test. Journal of Material Processing Technologies 160 (2004) 43-53

[10]H. Atkinson, A. Rassili, Thixoforming Steel, Shaker Verlag, Aachen 2010 